\title{
The Role of Community Factors in Predicting Depressive Symptoms Among Chinese Workforce: A Longitudinal study in Rural and Urban Settings
}

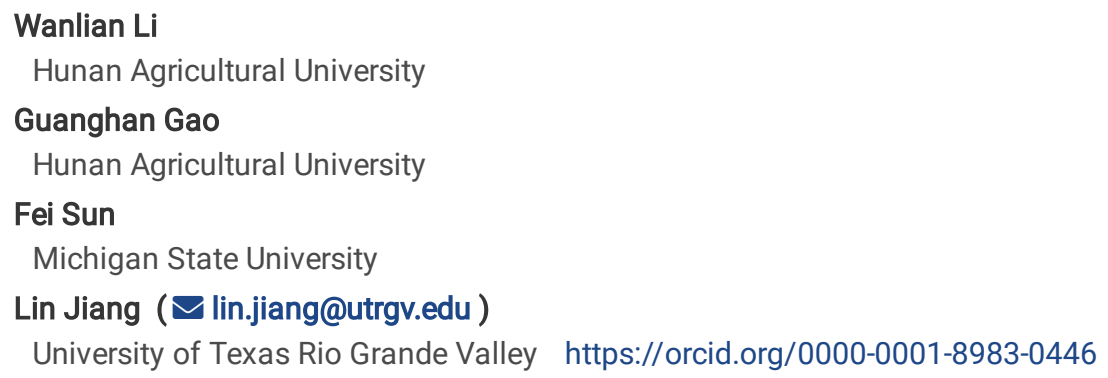

\section{Research}

Keywords: Disparities, workforce, depressive symptoms, community networks

Posted Date: August 20th, 2020

DOI: https://doi.org/10.21203/rs.3.rs-59644/v1

License: @ (i) This work is licensed under a Creative Commons Attribution 4.0 International License. Read Full License 


\begin{abstract}
Background: The dual urban-rural division system in China has led to distinguishes in economic development, medical services, and education as well as in mental health disparities. This study examined whether community factors (community cohesion, supportive network size, foreseeable community threat, and medical benefits coverage) predict the depressive symptoms of Chinese workers and how community factors may work differently in rural and urban settings.
\end{abstract}

Methods: This secondary data analysis was conducted using data from the 2014 and 2016 China Labor-force Dynamics Survey (CLDS). The sample includes 6157 rural workers and 2983 urban workers.

Results: The results indicate that rural workers have higher levels of depressive symptoms than urban workers. Medical benefits coverage predicts depressive symptoms of rural workforces $(B=-.326, p<.10)$, and community supportive network size predicts depressive symptoms of urban workforces $(B=-.531, p<.01)$.

Conclusions: Policymakers may reduce depressive symptoms of rural labor through improved coverage of medical benefits. In urban areas, efforts can be made to strengthen community supportive network for the urban labor force.

\title{
1. Background
}

\subsection{Urban and rural differences in depressive symptoms}

At the end of the 1950s, the 'Regulations of the People's Republic of China on Household Registration' were promulgated and implemented. It marked the emergence of a dual urban-rural division system in China, which remains influential to date (Gong, 2018). This has led to differences in economic development, medical services, and education as well as in mental health disparities between urban and rural areas (Knight \& Song, 1999; Paykel et al., 2000; Wang, 2004; Liu et al., 2007; Fu \& Ren, 2010). For example, rural workers have been found to report higher depressive symptoms than urban workers (Li et al. 2018; Probst et al. 2006).

\subsection{Impact of community factors on depressive symptoms}

Existing literature has highlighted an array of demographic and socioeconomic factors on depressive symptoms. Lower-income, lower education, and unemployment have been associated with depressive symptoms (Andersen et al., 2009; Romans et al., 2011; Shi et al., 2014) while higher depressive symptoms tend to be more common among women and young people (Fang et al., 2019; Gomez-Baya et al., 2017; Li et al., 2018). The effect of education on depressive symptoms is mixed, as literature reveals that both educated as well as relatively less educated people exhibit depressive symptoms (Romans et al., 2011). Growing research is interested in uncovering the environmental influence on workers' depressive symptoms. The rest of this section entails definitions and discussions around concepts that are associated with some of the community factors in question.

Community medical care. It refers to the level of medical services and medical security. There is an unequal level of medical and health services among communities in terms of medical prevention, health care, etc. (Van Dis, 2004; Wang, 2004; Zhang, 2000). Residents with adverse health status have higher depressive symptoms (Probst et al., 2006; Romans, 2011). Chiu \& Yang (2019) also demonstrated that there is a significant relationship between the level of medical insurance and psychological conditions. To this extent, residents with higher health insurance levels have more positive mental conditions.

Community relationships. These relationships reflect community cohesion and supportive network size. Previous research has found that older Chinese population with high community cohesion reported fewer depressive symptoms. Therefore, community cohesion can effectively slow down depressive symptoms in older Chinese people (Sun et al., 2019; Wang, 2017). However, Yamaguchi, Inoue, Shinozaki, Saito, Takagi, Kondo, \& Kondo (2019) found that community cohesion was not associated to depressive symptoms. Similarly, Haseda et al. (2018) also found that the effect of community cohesion on depressive symptoms was not significant.

Supportive network size. Previous research has demonstrated that participants with higher social support, especially support from friends and neighbors (Chen et al., 2016) reported less depressive symptoms (Zapata et al., 2017; Romans et al., 2011). Analyzed data from a national survey in Australia, Werner-Seidler et al. (2017) found that people who interacted with friends less than once a month were 2.19 times more likely to have depressive symptoms, and those without family support had a 3.47 times greater chance of having depressive symptoms.

Foreseeable community threat. A person's perception of the community shapes his/her understanding of community risks (Leverentz et al., 2018). More than $50 \%$ of men think their community is at risk, and less than half of women share similar perception (De Wet et al., 2018). Arthur et al. (2018) found that the when a person has a higher perceived community risk, he/she is more is prone to an unhealthy disease.

Page 2/11 
However, Moore et al. (2016) found that when a person feels safer in the community, the less their depressive symptoms. Similarly, Flórez et al. (2016) indicated that the more a person perceives security in their neighborhood, the less their psychological distress.

Existing research has alluded to the possible different effects of community on people's depressive symptoms, and yet, such effects have not been empirically tested for any population of Chinese workers. The first research question of this study is to identify the role of different community factors in predicting depressive symptoms of the labor force.

\subsection{Urban-rural differences in community factors}

The term "community" as used in this article refers to a variety of social relationships and social groups composed of people living in a particular place and a regional living community consisting of various social activities (Jiang \& Hu, 2002). This local living community includes both rural and urban communities. Compared with urban counterparts, rural residents are more willing to help each other even financially. They also tend to perceive a higher community cohesion and a larger supportive network size (Magadi, 2016; Zhang, 2001). On the other hand, urban residents generally are more likely to report foreseeable community threats such as public safety and environmental pollution than rural residents (Wang, 2010).

Additionally, China's urban-rural division system leads to differences in the management and quality of social services between urban and rural communities (Wang et al., 2018). For example, social security, social welfare assistance, health care, and health insurance are provided with higher quality in urban communities than they are in rural communities (Chen et al., 2013). Similarly, the Chinese urban labor force has wider access to health insurance options than rural counterparts.

Therefore, there is empirical evidence to support urban-rural differences in community cohesion, supportive network size, foreseeable community threat, and medical insurance coverage among Chinese workers. However, existing studies mostly used cross-sectional data, and the causality between the community factors and depressive symptoms cannot be determined. Longitudinal studies are needed to explore the causal relationship between variables and predictive ability. Our second research question centers on whether urban-rural differences in these community factors have different effects on labors' depressive symptoms. The foregoing underscores the two objectives of this project: 1) to identify the role of different community factors in predicting depressive symptoms of the labor force, and 2) to ascertain whether urban-rural differences in these community factors have different effects on labors' depressive symptoms.

\section{Methods}

\subsection{Data}

This was a secondary data analysis by using the 2014 and 2016 data from China Labor-force Dynamics Survey (CLDS). The survey was hosted by the Social Science Survey Center of Sun Yat-sen University and approved by the ethic committee at Sun Yat-sen University. A total of 29 colleges and universities participated in the follow-up survey conducted in 29 provinces and cities, "excluding Hong Kong, Macao, Taiwan, Tibet, and Hainan" (Li, Sun, Li, \& Durkin, 2019, p. 1251). The survey used a multistage cluster, stratified, and PPS sampling method that is proportional to the size of the labor force. Multistage random sampling was performed step by step according to the province, city, county (district), township, and village. Data for the survey was collected using the Computer Assisted Personal Interviewing (CAPI) as interviewers conducted face-to-face interviews.

A total of 23,594 individual labor questionnaires were surveyed in 2014, and 21,086 individual labor questionnaires were surveyed in 2016 . By selecting the individual data interviewed in 2014 and successfully tracking the interviews in 2016, a total of 9,140 individual samples were selected, including 6157 rural labor force samples and 2983 urban labor force samples. All predictors (independent and control variables) were from 2014 data.

\subsection{Measures}

\subsubsection{Dependentvariable}

The depressive symptoms were measured in the 2016 survey by using the Center for Epidemiological Studies Depression scale (Radloff, 1977). It consisted of 20 items measuring the frequency over the past weeks the participants experienced symptoms associated with depression. For example, the 20 items include "upset by trivial matters", "do not want to eat", and "even with the help of family and friends, I still can't get rid of my distress", etc. Frequencies range from 0 to 3 for each question: $0=$ No / Basically none (less than one day), 1=Rare (1-2 days), 2=Frequent (3-4 days), and 3=Almost always (5-7 days). Scores range from 0 to 60, with higher scores indicating more depressive symptoms. Cronbach's Alpha of the depressive symptoms factor is 0.945 in 2016. 


\subsubsection{Independent variable-community factors.}

Community cohesion was measured by three questions, asking the respondent about 'How familiar are you with the neighborhood and other residents of this community (village)?'; 'Do you trust the neighborhoods and other residents of this community (village)?'; 'Do you and your neighbors and other residents help each other?' The options for the three questions are 5-level scales ranging from 'very few' (1) to 'very much' (5). The total score ranged from 3 to 15. The community cohesion's Cronbach's Alpha was 0.799.

A four-points Likert scale with six items were used to measure foreseeable community threat. Participants assessed the possibility of a community threat that would occur to them in the next five years from 1 (very unlikely) to 4 (very likely). The six questions included "the likelihood of being unemployed, victimized by a criminal, attacked by a terrorist, affected by a contagious disease, subject to adulterated medications or food, and exposed to environmental pollution" (Li, Sun, Anderson, 2018, p.320). The total score ranged from 4 to 24 ( $L i$, Sun, Anderson, 2018), with higher scores indicating a more foreseeable community threat. The Cronbach's Alpha of the foreseeable community threat factor was 0.831 .

Community supportive network size was measured by four open-ended questions: among people that the participants feel close to in their local living community (Li, Sun, Li, Durkin, 2019): “1) how many they can ask for help; 2) how many they can share personal stories; 3) how many they can discuss important matters; 4) how many can lend them RMB 5000 (about \$720) or above" (Li, Sun, Li, Durkin, 2019, p.1521). Then none people was code as 1; $1-2$ people was coded 2; $3-5$ people was coded 3; 6-9 people was coded 4; and 10 and above people was coded as 5 (Li, Sun, Li, Durkin, 2019). The high the cumulative scores of four questions indicated a large community supportive network size. The Cronbach's alpha of community supportive network size was 0.869 .

Medical benefits coverage was evaluated by the insurance types, which were ranked based upon the levels of benefits it entailed. For example, we used " 1 " to represent new rural medical cooperative insurance, which represented the lowest level of coverage, and used " 5 " to represent government-supported medical, representing the highest level of coverage (Li, Sun, \& Anderson, 2018). One score was added if any participant indicated that he or she had subsided or private insurance. Two scores were increased if they had both (Li, Sun, Anderson, 2018). Therefore, medical coverage was ranked from 1 to 7 .

\subsubsection{Control variables}

Control variables included 2014 depressive symptoms and socio-demographic variables such as gender, age, and education. Different from the survey in 2016, the 2014 survey did not use a standardized measurement of depressive symptoms. We selected one single question from the 2014 depressive symptom measure as sort of a baseline indicator of depressive symptoms. Because this item most captured depressive symptom as it asked the respondent about whether "your work or daily life had been affected due to emotional problems in the past month" on a 5-level scales ranging from "very few" (1) to "very much" (5). Gender was a dichotomous variable (male =1; female =2). Age was a continuous variable from 15 to 71 . Educational level contained five categories: never attended school =1; primary $/$ private school =2; middle school (junior high school, ordinary high school, vocational high school, technical school, technical secondary school) $=3$; university (college, undergraduate) $=4$; and master's degree and above $=5$.

The participants were asked to rate their health condition (self-rated health) on a five-level scale from "very unhealthy" (1) to "very healthy" (5). The self-rated class reflects the level of the participants' status in politics, economics, education, etc. by asking the respondents to rate "their perceived social class on a Likert scale from 1 (lowest) to 10 (highest)" (Li, Sun, Anderson, 2018, P. 321). Furthermore, a 5-point Likert scale, which was ranked from "not satisfied at all" (coded as 1 ) to "very satisfied" (coded as 5), was used to measure self-perceived job satisfaction (Li, Sun, Anderson, 2018).

\subsection{Analytical Strategy}

The characteristics of the sample were described by using descriptive analysis. Then, we used a t-test to ascertain the difference in community factors and depressive symptoms between urban and rural. We used the correlation analysis to present the relationships among the independent variables, control variables, and dependent variables on the bivariate level. We conducted a regression analysis was conducted to ascertain the effect of factors on the dependent variables. We used the a level of $\leq 0.05$ as statistical significance in correlation analysis and a level of $\leq 0.1$ as statistical significance in regression analysis. All analyses were conducted using SPSS 24.0

\section{Results}

Table 1 presents the overall characteristics of the participants and t-test results. T-test showed that there were differences between urban and rural depressive symptoms and community factors. Rural labor reported more depressive symptoms than urban labor in 2016 . Table 1 also 
shows that compared to the urban labor force, the rural labor force had more married people as well as an older population. The rural labor force also had more job satisfaction and higher community cohesion compared to their urban counterpart. The results further revealed that education levels, self-rated health, self-rated class, and self-perceived class were all significantly lower for the rural labor force. More so, the rural labor force had far less foreseeable community threat, less medical insurance coverage, and smaller supportive network size compared to the urban labor force.

Table 1

Sample Characteristics

\begin{tabular}{|c|c|c|c|}
\hline & Rural workers $₫ N=6157 \rrbracket$ & Urban workers $₫ N=2983 \rrbracket$ & $\begin{array}{l}\text { T test } \\
\text { p-value }\end{array}$ \\
\hline & $\mathrm{M}(\mathrm{SD}) /$ Percentage & $\mathrm{M}(\mathrm{SD}) /$ Percentage & \\
\hline \multicolumn{4}{|l|}{ Dependent variable } \\
\hline 2016 Depressive symptoms & $8.06 \varangle 9.50 \rrbracket$ & $6.40 \rrbracket 8.32 \rrbracket$ & $<0.001$ \\
\hline \multicolumn{4}{|c|}{ Independent variable-Community Factors } \\
\hline Community cohesion & $14.92 \llbracket 2.40 \rrbracket$ & $13.03(2.64)$ & $<0.001$ \\
\hline Foreseeable community threat & $9.07 \rrbracket 3.25 \rrbracket$ & 10.44(3.65) & $<0.001$ \\
\hline Supportive network size & $2.78 \otimes 1.12 \rrbracket$ & $2.84(1.10)$ & 0.012 \\
\hline Medical insurance coverage & 1.19ه0.69『 & $2.59(1.54)$ & $<0.001$ \\
\hline \multicolumn{4}{|l|}{ Control variable } \\
\hline Age & 47.16ه13.00ه & $42.98 \rrbracket 12.66 \rrbracket$ & $<0.001$ \\
\hline Female & $53.1 \%$ & $55.1 \%$ & 0.055 \\
\hline Married & $88.5 \%$ & $82.4 \%$ & $<0.001$ \\
\hline Education & 2.47ه0.99囚 & $3.55 \rrbracket 1.11 \rrbracket$ & $<0.001$ \\
\hline no formal education & $17.8 \%$ & $4.1 \%$ & \\
\hline elementary school & $33.4 \%$ & $12.5 \%$ & \\
\hline middle school & $35.3 \%$ & $32.5 \%$ & \\
\hline high school & $11.0 \%$ & $26.6 \%$ & \\
\hline college and above & $2.5 \%$ & $24.4 \%$ & \\
\hline Self-rated health & $3.54 \rrbracket 1.03 \rrbracket$ & $3.78(0.90)$ & $<0.001$ \\
\hline Self-rated class & $4.42 \otimes 1.66 \rrbracket$ & $4.74(1.66)$ & $<0.001$ \\
\hline Self-perceived job satisfaction & $3.37 \rrbracket 0.81 \rrbracket$ & $3.43(0.78)$ & 0.002 \\
\hline 2014 Depressive symptoms & $1.61 ه 0.88 \rrbracket$ & $1.50(0.78)$ & $<0.001$ \\
\hline
\end{tabular}

Note: Rural was coded as "1"; urban was coded as "2".

Table 2 shows that rural labor reported more depressive symptoms than urban labor. Workers with more depressive symptoms in 2014older, female, and less educated reported more depressive symptoms. Both urban and rural workers who had poorer self-rated health, lower self-rated class, and lower self-perceived job satisfaction reported more depressive symptoms. At the community level, people with more depressive symptoms also reported lower community cohesion, less community support network, higher threat, and lower medical insurance coverage. 
Table 2

Bivariate Correlates of depressive symptoms

\begin{tabular}{|c|c|c|c|c|c|c|c|c|c|c|c|c|}
\hline & 2 & 3 & 4 & 5 & 6 & 7 & 8 & 9 & 10 & 11 & 12 & $\begin{array}{l}2016 \\
\text { CES-D }\end{array}$ \\
\hline $\begin{array}{l}1.2014 \\
\text { depressive } \\
\text { symptoms }\end{array}$ & $-.063^{\star \star}$ & $.094 * \star$ & $.056 * \star$ & -.131 ** & $-.323^{\star \star}$ & -.136 ** & -.136 ** & $-.043^{\star *}$ & $.049 \star \star$ & $-.053^{\star \star}$ & $-.063^{\star \star}$ & $.234^{\star \star}$ \\
\hline 2.Urban & & 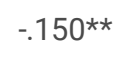 & .020 & $.443^{\star \star}$ & $.114^{\star \star}$ & $.091 \star \star$ & $.035^{\star \star}$ & $-.337 \star \star$ & .186 ** & $.026^{*}$ & $.533^{\star \star}$ & $-.085^{\star \star}$ \\
\hline 3.Age & & & $-.048 \star \star$ & $-.400 \star \star$ & 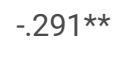 & $-.039 \star \star$ & $.052^{\star \star}$ & $.196 \star \star$ & $-.117 \star \star \star$ & $-.025^{\star}$ & $-.055^{\star \star}$ & $.077^{\star *}$ \\
\hline 4.Female & & & & $-.162^{\star \star}$ & $-.057 \star \star$ & .019 & -.017 & 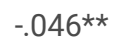 & $-.028 \star \star$ & $-0.89 \star \star$ & -.015 & .091 ** \\
\hline 5.Education & & & & & $.248 \star \star$ & $.122^{\star \star}$ & $.087 * \star$ & $-.221^{\star \star}$ & $.123^{\star \star}$ & $.136 * \star$ & .458 & $-.151^{\star \star *}$ \\
\hline $\begin{array}{l}\text { 6.Self-rated } \\
\text { health }\end{array}$ & & & & & & $.256^{\star \star}$ & $.111^{\star \star}$ & $.060 \star \star$ & $-.055^{\star \star}$ & $.156^{\star \star}$ & $.071^{\star \star}$ & -.250 ** \\
\hline $\begin{array}{l}\text { 7.Self-rated } \\
\text { class }\end{array}$ & & & & & & & $.185^{\star \star}$ & $.088^{\star \star}$ & $-.114^{\star \star}$ & $.164^{\star \star}$ & $.083^{\star \star}$ & $-.143^{\star \star}$ \\
\hline $\begin{array}{l}\text { 8.Self- } \\
\text { perceived } \\
\text { job } \\
\text { satisfaction }\end{array}$ & & & & & & & & $.088^{\star \star}$ & $-.093^{\star \star}$ & $.050 * \star$ & $.078 \star \star$ & $-.087 \star \star$ \\
\hline $\begin{array}{l}\text { 9. Community } \\
\text { cohesion }\end{array}$ & & & & & & & & & $-.213^{\star \star}$ & $.253^{\star \star}$ & $-.242 \star \star$ & $-.024^{\star}$ \\
\hline $\begin{array}{l}\text { 10.Community } \\
\text { threat }\end{array}$ & & & & & & & & & & $-.042^{\star \star}$ & $.095 \star \star$ & $.034^{\star *}$ \\
\hline $\begin{array}{l}\text { 11.Supportive } \\
\text { network size }\end{array}$ & & & & & & & & & & & $.064^{\star \star}$ & $-.095^{\star \star}$ \\
\hline $\begin{array}{l}\text { 12.Medical } \\
\text { insurance } \\
\text { coverage }\end{array}$ & & & & & & & & & & & & $-.095^{\star \star}$ \\
\hline
\end{tabular}

Note**. Correlation is significant at the 0.01 level (2-tailed).

*. Correlation is significant at the 0.05 level (2-tailed).

The results of the four regression models are shown in table 3. Model 1 and model 2 tested the factors associated with depressive symptoms of rural labor. Model 1 shows that for the rural labor force, their depressive symptoms in 2014 were significantly positively correlated with their depressive symptoms in 2016. It also shows that gender, education level, self-rated class, and self-rated health have significant effects on 2016 depressive symptoms. Workers in rural areas who were female, had a less formal education, lower social class, and poorer self-rated health reported higher levels of depressive symptoms. Model 2 added the community factors. The change in adjusted R-square values form Model 1 to Model 2 was not significant. However, the medical insurance coverage predicts depressive symptoms of rural labor. Rural labor with lower medical insurance coverage reports more depressive symptoms.

Model 3 and model 4 tested the influence of control variables and independent variables on depressive symptoms of urban labor. Model 3 shows that for urban labor, the baseline depressive symptom in 2014 were significantly positively correlated with depressive symptoms in 2016. Urban workers who were younger, female, lower education level, lower social class, poorer self-rated health, and lower self-perceived job satisfaction reported more depressive symptoms. Model 4 controls the variables of models 3 . The results show that the community supportive network size predicts the depressive symptoms of urban labor. The change in adjusted R-square values form Model 3 to Model 4 was significant $(p<.01)$. The smaller community supportive network size is, the more depressive symptoms are reported. 
Table 3

Regression analysis results

\begin{tabular}{|c|c|c|c|c|c|c|c|c|}
\hline & \multicolumn{4}{|c|}{ Rural workers $\mathbb{N}=6157 \rrbracket$} & \multicolumn{4}{|c|}{ Urban workers $₫ N=2983 \rrbracket$} \\
\hline & \multicolumn{2}{|l|}{ Mode1 } & \multicolumn{2}{|l|}{ Model 2} & \multicolumn{2}{|l|}{ Model 3} & \multicolumn{2}{|l|}{ Model4 } \\
\hline & $\mathrm{B} \otimes \mathrm{SD} \bigotimes$ & P-value & $\mathrm{B} \otimes \mathrm{SD} \rrbracket$ & P-value & $\mathrm{B} \otimes \mathrm{SD} \bigotimes$ & P-value & $\mathrm{B} \bigotimes \mathrm{SD} \bigotimes$ & P-value \\
\hline \multirow[t]{2}{*}{2014 Depressive symptoms } & $1.990 \rrbracket 0.156 \rrbracket$ & $<0.001$ & 1.976 & $<0.001$ & 1.364 & $<0.001$ & 1.369 & $<0.001$ \\
\hline & & & $\otimes 0.156 \rrbracket$ & & $\llbracket 0.220 \rrbracket$ & & $\varangle 0.220 \rrbracket$ & \\
\hline \multirow[t]{2}{*}{ Age } & $0.012 \varangle 0.012 \rrbracket$ & 0.330 & $0.014 \llbracket 0.012 \rrbracket$ & 0.251 & $-0.059 \llbracket 0.016 \rrbracket$ & $<0.001$ & -0.051 & 0.002 \\
\hline & & & & & & & $\triangle 0.017 \rrbracket$ & \\
\hline \multirow[t]{2}{*}{ Female } & $1.493 \rrbracket 0.269 \rrbracket$ & $<0.001$ & 1.488 & $<0.001$ & $0.555 \rrbracket 0.327 \rrbracket$ & 0.090 & 0.492 & 0.133 \\
\hline & & & $(0.270)$ & & & & $(0.328)$ & \\
\hline \multirow[t]{2}{*}{ Education } & $-0.524 \llbracket 0.148 \rrbracket$ & 0.001 & -0.450 & 0.003 & $-0.472 \varangle 0.162 \rrbracket$ & 0.004 & -0.347 & 0.057 \\
\hline & & & $(0.153)$ & & & & $(0.182)$ & \\
\hline \multirow[t]{2}{*}{ Self-rated health } & -1.489 & $<0.001$ & -1.451 & $<0.001$ & $-1.075 \llbracket 0.201 \rrbracket$ & $<0.001$ & -1.030 & $<0.001$ \\
\hline & $\nabla 0.140 \rrbracket$ & & $(0.142)$ & & & & $(0.203)$ & \\
\hline \multirow[t]{2}{*}{ Self-rated class } & $-0.387 \rrbracket 0.079 \rrbracket$ & $<0.001$ & -0.358 & $<0.001$ & -0.246 & 0.017 & -0.175 & 0.094 \\
\hline & & & $(0.081)$ & & $\nabla 0.103 \rrbracket$ & & $(0.105)$ & \\
\hline \multirow[t]{2}{*}{ Self-perceived job satisfaction } & $-0.128 \rrbracket 0.160 \rrbracket$ & 0.425 & -0.115 & 0.474 & -0.707 & 0.001 & -0.630 & 0.004 \\
\hline & & & $(0.161)$ & & $\nabla 0.216 \square$ & & $(0.217)$ & \\
\hline \multirow[t]{2}{*}{ Community cohesion } & & & -0.030 & 0.610 & & & -0.022 & 0.743 \\
\hline & & & $(0.058)$ & & & & $(0.067)$ & \\
\hline \multirow[t]{2}{*}{ Foreseeable community threat } & & & 0.033 & 0.419 & & & 0.074 & 0.112 \\
\hline & & & $(0.041)$ & & & & $(0.046)$ & \\
\hline \multirow[t]{2}{*}{ Supportive network size } & & & -0.131 & 0.284 & & & -0.505 & 0.001 \\
\hline & & & $(0.122)$ & & & & $(0.156)$ & \\
\hline \multirow[t]{2}{*}{ Medical insurance coverage } & & & -0.366 & 0.041 & & & -0.114 & 0.333 \\
\hline & & & $\otimes 0.179 \rrbracket$ & & & & $(0.118)$ & \\
\hline Adjusted R-square & 0.118 & & 0.119 & & 0.061 & & 0.065 & \\
\hline
\end{tabular}

\section{Discussion \& Conclusion}

Our results generally reveal that there is a significant difference between the depressive symptoms of rural and urban labor in China. To this extent, we found that rural labor has more depressive symptoms than urban labor. The following group of workers reported more depressive symptoms: older worker, female and less educated workers, workers with lower self-rated health, workers with lower medical insurance coverage as well as workers with lower self-rated class. Some community factors predict the depressive symptoms of the labor force.

The differences between urban and rural communities lead to differences in the impact of these community factors on the depressive symptoms in urban and rural labor. Depressive symptoms of rural workers were more affected by medical insurance coverage, while depressive symptoms of urban labor were affected by supportive network size. Specifically, rural labors with lower medical insurance coverage indicated more depressive symptoms. Urban labors with smaller community support sizes indicated more depressive symptoms.

Medical insurance coverage was a significant predictor of depressive symptoms for rural workers. However, it was found to have no effect on urban labor. The reason may be that the rural labor force is facing more pressure to pay for medical treatment (Yao et al., 2014). For example, 
the reimbursement scope and amount of reimbursement medical insurance in rural areas was significantly lower than that in urban China. This disparity matters because medical benefits have huge implications on workers' mental health. A high level of medical security can significantly promote mental health (Zhang \& Wu, 2018). If the labor force changes from low-level medical insurance to higher-level medical insurance, it can substantially improve their health (Ma et al., 2015).

Our findings also show that the supportive network size only has a significant impact on the depressive symptoms of the urban labor force. The possible reason is that the urban community environment itself is less emotional and trustworthy than the rural community (Lin et al., 2018; Wang et al., 2016). At the same time, the urban labor force's job satisfaction is lower than the rural labor force, and urban labors may face more work pressure. Work pressure may increase the level of negative emotions. If urban labors fail to seek help to deal with their negative emotions, their mental health will be affected (Jiang, 2006; Tang et al.; 2011). However, empathy and subjective psychological support from others can help urban labors effectively reduce their negative emotions (Tu \& Guo, 2011).

The effects of foreseeable community threat and community cohesion on labors' depressive symptoms were not significant in either rural or urban settings. Previous research using cross-sectional data found that community cohesion could alleviate depressive symptoms (Chao et al., 2016; Fullerton et al., 2015). However, our study, which used the longitudinal prediction data, indicated that community cohesion could not predict depressive symptoms. This may be because individuals have adapted to the community environment as they reside longer in their community (Moore et al., 2016). Therefore, the long-term effects of community cohesion and community threat on individual emotions are not significant. This also shows that the effect of community cohesion and community threat on people's emotions needs to be continuously observed and studied.

The results further reveal that the rural labor force has more depressive symptoms than their urban counterparts. The roles of community factors on the depressive symptoms manifested differently among urban and rural labor force. These results not only provide empirical data to understand the various factors affecting the depressive symptoms of China's urban and rural labor force but also present policy suggestions for China's urban and rural governance and community construction. In the development of rural communities, it is crucial to reduce the gap between urban and rural medical insurance coverage. Thereby decreasing the pressure of out-of-pocket payment among rural laborers may lessen the depressive symptoms of rural laborers.

Furthermore, urban community governance may consider organizing inclusive community activities and broadening the supportive network size of the urban labor force. Thus, urban labors may build a supportive network that can seek help, share their minds, and relieve stress. Ultimately, the supportive system may reduce the depressive symptoms of the urban labor force due to work pressure.

\section{List Of Abbreviations}

China Labor-force Dynamics Survey (CLDS)

Computer Assisted Personal Interviewing (CAPI)

\section{Declarations}

\subsection{Ethics approval and consent to participate}

This is a secondary data analysis. No human being and animals were involved. The secondary data used was de-identified data. The dataset has been stripped of all identifying information and there is no way that it could be linked back to the subjects from whom it was originally collected. The ethic committee at Hunan Agricultural University approved this IRB exempt.

\subsection{Consent for publication}

Not applicable.

\subsection{Availability of data and materials}

The datasets generated and/or analysed during the current study are available in the Sun-Yatsen University Social Science Research Center repository, http://engcss.sysu.edu.cn/Data

\subsection{Competing interests}

Page $8 / 11$ 
The authors declare that they have no competing interests.

\subsection{Funding}

No funding

\subsection{Authors' contributions}

WLL: Conceptualization, Methodology, Writing- Original draft preparation

GHG: Formal analysis, Writing- Original draft preparation

FS: Supervision, Writing- Reviewing and Editing

LJ: Writing- Reviewing and Editing

\subsection{Acknowledgments}

The authors would like to acknowledge the support of Dr. He Cai at the Social Science Research Center of Sun-Yatsen University for providing the data set.

\section{References}

1. Andersen I, Thielen K, Nygaard E, Diderichsen F. Social inequality in the prevalence of depressive disorders. Journal of Epidemiology \& Community Health.2009; doi:10.1136/jech.2008.082719.

2. Arthur K, Spencer-Hwang R, Knutsen S, Shavlik D, Soret S, Montgomery S. Are perceptions of community safety associated with respiratory illness among a low-income, minority adult population. BMC Public Health. 2018; doi:10.1186/s12889-018-5933-4.

3. Chao S. Outdoor activities and depressive symptoms in displaced older adults following natural disaster: Community cohesion as mediator and moderator. Aging \& Mental Health. 2016; doi:10.1080/13607863.2015.1044940.

4. Chen R, Zhou Y, Shen H, Zhao Y. Studies on differences of China' urban and rural communities development. Urban Development Studies. 2013;12:50-55.

5. Chen Y, Wong G, Lum T, Lou V, Ho A, Luo H, et al. Neighborhood support network, perceived proximity to community facilities and depressive symptoms among low socioeconomic status Chinese elders. Aging \& Mental Health. 2016; doi:10.1080/13607863.2015.1018867.

6. Chiu S, Yang Z. Influence of family income and medical insurance coverage on health-related quality of life and optimism in cancer patients at a Hong Kong private hospital: A cross-sectional study. Psycho-Oncology. 2019; doi:10.1002/pon.5175.

7. De Wet N, Somefun O, Rambau N. Perceptions of community safety and social activity participation among youth in South Africa. PLoS one. 2018; doi:10.1371/journal.pone.0197549.

8. Fang M, Chen J, Guo L, Ma X. Gender differences in geriatric depressive symptoms in rural China: the role of physical housing environments and living arrangements. International Journal of Environmental Research and Public Health. 2019; doi:10.3390/ijerph16050774.

9. Flórez K, Ghosh-Dastidar M, Beckman R, De La Haye K, Duru O, Abraído-Lanza, et al. The power of place: Social network characteristics, perceived neighborhood features, and psychological distress among African Americans in the historic Hill District in Pittsburgh, Pennsylvania. American Journal of Community Psychology. 2016; doi:10.1002/ajcp.12086.

10. Fu Q, Ren Q. Educational inequality under China's rural-urban divide: The hukou system and return to education. Environment and Planning A. 2010; doi:10.1068/a42101

11. Fullerton C, Ursano R, Liu X, McKibben J, Wang L, Reissman D. Depressive symptom severity and community collective efficacy following the 2004 Florida hurricanes. PloS one. 2015; doi:10.1371/journal.pone.0130863.

12. Gomez-Baya D, Mendoza R, Paino S, Gillham J. A two-year longitudinal study of gender differences in responses to positive affect and depressive symptoms during middle adolescence. Journal of Adolescence. 2017; doi:10.1016/j.adolescence.2017.01.005.

13. Gong W. On the reform of household registration system in the process of rural revitalization from historical perspective. Journal of Chinese Academy of Governance. 2018;3:19-25+,152-153.

Page $9 / 11$ 
14. Haseda M, Kondo N, Takagi D, Kondo K. Community social capital and inequality in depressive symptoms among older Japanese adults: A multilevel study. Health \& Place.2018; doi:10.1016/j.healthplace.2018.04.010.

15. Jiang Y. Relationship between individual control points, work stress and job satisfaction. Economic Management. 2006;21:43-48.

16. Jiang Z, Hu H. A short history for the concept of social community. Journal of China Youth College for Political Sciences. 2002;4:121-124.

17. Knight J, Song L. The rural-urban divide: Economic disparities and interactions in China. OUP Catalogue; 2000.

18. Leverentz A, Pittman A, Skinnon J. Place and perception: Constructions of community and safety across neighborhoods and residents. City \& Community. 2018; doi:10.1111/cico.12350.

19. Li W, Sun F, Anderson S. Differences in depressive symptoms between rural and urban Chinese labor force: The mediating effects of community factors.

20. International Journal of Social Psychiatry. 2018; doi:10.1177/0020764018754596.

21. Li W, Sun F, Li Y, Durkin D. Work stress and depressive symptoms in Chinese migrant workers: The moderating role of community factors. Journal of Immigrant and Minority Health. 2018; doi:10.1007/s10903-018-0843-1.

22. Lin L, Meng M, Yang Y, He S. Comparisons of aging in place behavior between urban and rural areas based on resident normalcy: A case of Yaohua and Xinji Communities. Modern Urban Research. 2018;8:21-27.

23. Liu M, Zhang Q, Lu M, Kwon C, Quan H. Rural and urban disparity in health services utilization in China. Medical Care. 2007;

24. doi:10.1097/MLR.0b013e3180618b9a.

25. Ma C, Gu H, Sun H. Does higher grade of medical insurance lead to better health: Evidence from nature experiment of urban-rural integrated medical insurance system. Journal of Public Management. 2015;2:106-118+157-158.

26. Magadi, M. A. Understanding the urban-rural disparity in HIV and poverty nexus: the case of Kenya. Journal of Public Health, 2016; doi:10.1093/pubmed/fdw065.

27. Moore K, Hirsch J, August C, Mair C, Sanchez B, Roux A. Neighborhood social resources and depressive symptoms: Longitudinal results from the multi-ethnic study of atherosclerosis. Journal of Urban Health. 2016; doi:10.1007/s11524-016-0042-0.

28. Paykel E, Abbott R, Jenkins R, Brugha T, Meltzer H. Urban-rural mental health differences in Great Britain: Findings from the National Morbidity Survey. Psychological Medicine. 2000; doi:10.1017/S003329179900183X.

29. Probst J, Laditka S, Moore C, Harun N, Powell M, Baxley E. (2006). Rural-urban differences in depression prevalence: implications for family medicine. Family Medicine. 2006;9:653-660.

30. Radloff L. The CES-D scale: A self-report depression scale for research in the general population. Applied Psychological Measurement. 1977; doi:10.1177/014662167700100306.

31. Romans S, Cohen M, Forte T. Rates of depression and anxiety in urban and rural Canada. Social Psychiatry and Psychiatric Epidemiology. 2011; doi:10.1007/s00127-010-0222-2.

32. Shi J, Zhang Y, Liu F, Li Y, Wang J, Flint J, et al. Associations of educational attainment, occupation, social class and major depressive disorder among Han Chinese women. PloS one. 2014; doi:10.1371/journal.pone.0086674.

33. Sun F, Li W, Jiang L, Lee J. Depressive symptoms in three Chinese older workforce groups: the interplay of work stress with family and community factors. International Psychogeriatrics. 2019; doi:10.1017/S1041610219000528.

34. Tang C, Yi B, Zhao L. Negative emotions, emotional expression norms, and psychological health of employees under work stress. Human Resource Development of China. 2011;11:95-99.

35. Tu Y, Guo Y. The influence of life-events on negative emotions: Social support as a moderator and coping style as a mediator. Chinese Journal of Clinical Psychology. 2011;5:652-655.

36. Wang F. A research on risk society and the residents' risk perception in contemporary china. The Journal of Shanghai Administration Institute. 2010;2:83-91.

37. Wang J. Rural-urban differences in the prevalence of major depression and associated impairment. Social Psychiatry and Psychiatric Epidemiology. 2004; doi:10.1007/s00127-004-0698-8.

38. Wang M, Zhao M, Zhu H. Individualization phenomenon in the process of neighborhood space transformation-A case study of concentrated area of overseas Chinese in Guangzhou. World Regional Studies. 2016;4:132-143.

39. Wang Y, Chen Y, Shen H, Morrow-Howell N. Neighborhood and depressive symptoms: A comparison of rural and urban Chinese older adults. The gerontologist. 2017; doi:10.1093/geront/gnx063.

40. Wang Z, Zhang X, Wu K. What Kind of Community is More Stable? An Empirical Study on the Influence of Heterogeneous Social Structure on Community Stability. Chinese Public Administration. 2018;6:100-107.

41. Werner-Seidler A, Afzali M, Chapman C, Sunderland M, Slade T. The relationship between social support networks and depression in the 2007 National Survey of Mental Health and Well-being. Social Psychiatry and Psychiatric Epidemiology. 2017; doi:10.1007/s00127-017-

Page 10/11 
1440-7.

42. Van Dis, J. Where we live: health care in rural vs urban America. JAMA. 2003; doi: 10.1001/jama.287.1.108-JMS0102-2-1.

43. Yamaguchi M, Inoue Y, Shinozaki T, Saito M, Takagi D, Kondo K, et al. Community social capital and depressive symptoms among older people in Japan: A multilevel longitudinal study. Journal of Epidemiology. 2019; doi:10.2188/jea.JE20180078.

44. Yao Y, Liu B, Liu G, Zang B. Medical Insurance, Household Registration System and Healthcare Utilization-Evidences from CHARLS Data Analysis. Insurance Studies. 2014;6:105-116.

45. Zapata Roblyer M, Carlos F, Merten M, Gallus K, Grzywacz J. Psychosocial factors associated with depressive symptoms among Latina immigrants living in a new arrival community. Journal of Latina/o Psychology. 2017; doi:10.1037/lat0000068.

46. Zhang P, Too G, Irwin K. Utilization of preventive medical services in the United States: a comparison between rural and urban populations. The Journal of Rural Health. 2000; doi:10.1111/j.1748-0361.2000.tb00485.x.

47. Zhang Q, Wu C. Types of Medical Insurance and Health Improvement of Labor Force-Based on the evidence from CLDS empirical data. Journal of Sichuan University of Science \& Engineering (Social Sciences Edition). 2018;5:1-16.

48. Zhang Y. Comparative Study on the Support of Social Network for Senior Citizen: A case study in Xiamen. Sociological Research. 2001;4:11-21. 